\title{
PENGARUH EKSTRAK SELEDRI (Apium graveolens L.) TERHADAP KELARUTAN KALSIUM DALAM BATU GINJAL
}

\author{
Effect of Celery (Apium graveolens L.) Extract Against the Solubility of \\ Calcium Kidney Stones
}

\author{
*Evie Kurnia Maya Dewi, Daud K. Walanda, dan Sri Mulyani Sabang
}

Pendidikan Kimia/FKIP - Universitas Tadulako, Palu - Indonesia 94118

Received 10 June 2016, Revised 11 July 2016, Accepted 11 August 2016

\begin{abstract}
Celery (apium graveolens L.) contains chemicals that can be used as traditional medicine for various treatments. The research objective is to determine the effect of celery (apium graveolens L.) extractsin dissolving calcium kidney stones and calcium to determine the relationship between the concentration of extract of celery (apium graveolens L.) with the solubility of calcium in the kidney stones. Determination of the solubility of calcium in an extract of celery is by flame fotometer. The concentration of the extract was varried into $1 \%, 5 \%, 10 \%, 15 \%$ and $20 \%$. To a concentration of $1 \%$ can dissolve the calcium as much as $15.104 \%$; concentration of $5 \%$ can dissolve the calcium as much as $18.708 \%$; concentration of $10 \%$ can dissolve the calcium as much as $23.683 \%$; concentration of $15 \%$ can dissolve the calcium as much as $28.869 \%$; and to a concentration of $20 \%$ can dissolve the calcium as much as $35.048 \%$. It can be concluded that celeries extract can dissolve calcium of kidney stones.
\end{abstract}

Keywords: Celery (apium graveolens L); calcium; kidney stone; solubility

\section{Pendahuluan}

Pemanfaatan tumbuhan sebagai obat sudah seumur dengan peradaban manusia. Tumbuhan itu sendiri memiliki banyak manfaat termasuk untuk obat berbagai penyakit. Penggunaan bahan alam sebagai obat cenderung mengalami peningkatan dengan adanya back to nature dan krisis ekonomi berkepanjangan yang mengakibatkan turunnya daya beli masyarakat terhadap obat-obat modern yang relatif mahal harganya (Ismadi, 1978).

Seiring dengan kemajuan dunia kesehatan dan teknologi, cara pengobatan penyakit batu ginjal banyak memberikan alternatif, baik dengan obat-obatan (obat sintesis maupun obat tradisional), operasi dan penyinaran khusus untuk batu ginjal. Banyaknya alternatif pengobatan tersebut para penderita penyakit batu ginjal lebih memilih mengkonsumsi obatobat sintesis, melakukan operasi, dan penyinaran yang memiliki daya reaksi yang cepat. Namun pengobatan tersebut bukanlah pengobatan yang murah melainkan pengobatan yang sangat

*Correspondence:

Evie Kurnia Maya Dewi

Program Studi Pendidikan Kimia, Fakultas Keguruan dan

Ilmu Pendidikan, Universitas Tadulako

email: evieekurnia@gmail.com

Published by Universitas Tadulako 2016 mahal, sedangkan kebanyakan masyarakat memiliki tingkat ekonomi menengah ke bawah, sehingga tidak semua penderita dapat melakukan pengobatan yang bereaksi dengan cepat tersebut. Adanya pengobatan tersebut membuat obat tradisional menjadi ketinggalan zaman, namun kenyataan membuktikan bahwa obat tradisional mempunyai banyak sekali keunggulan selain murah dan mudah didapat, yang lebih penting adalah tidak memiliki efek samping yang nyata, seperti yang ditimbulkan oleh pengobatan alternatif yang lain. Agar peranan obat tradisional dapat ditingkatkan, maka diperlukan upaya pengenalan, penelitian dan penggujian khasiat serta keamanannya (Ismadi, 1978). Terapi medis (penggunaan diuretik dan oabat-obatan lainnya), penggunaan lebih dari obat sintetik yang menghasilkan insiden yang lebih tinggi dari reaksi obat yang merugikan telah memotivasi masyarakat untuk kembali ke alam untuk obat yang aman (Rajat dkk., 2011).

Tumbuhan seledri (Apium graveolens L) merupakan salah satu tanaman berkhasiat yang banyak digunakan oleh masyarakat, juga sebagai penyedap dalam makanan (Rukmana, 1995). Seledri berkhasiat memacu enzim pencernaan 
dan kencing (diuretik), pereda kejang (antispasmodik), menurunkan kadar asam urat darah, antirematik, peluruh kencing (diuretik), peluruh kentut (karminatif), afrodisiak, penenang (sedatif), dan antihipertensi (Dalimartha, 2000). Kandungan kaliumnya yang cukup tinggi menyebabkan pengguna seledri tidak memerlukan penambahan kalium dari luar akibat efek diuretik dari yang dikonsumsinya (Dalimartha, 2002). Namun, seledri masih jarang digunakan oleh masyarakat untuk memperlancar pengeluaran air seni. Khasiatnya seledri diduga mempunyai daya larut yang baik, olehnya itu dapat menyembuhkan penyakit kencing batu karena ciri-ciri penderita batu ginjal ini salah satunya adalah susah buang air seni.

Penyakit batu ginjal juga dikenal sebagai Nefrolitiasis. Batu ginjal merupakan masalah umum di seluruh dunia. Penyakit ini mempengaruhi sekitar $10 \%$ dari populasi dunia. Cara

pengobatan ini membutuhkan biaya yang sangat mahal. Pembentukan dimulai ketika kristal kalsium oksalat, komponen utama dari batu ginjal, dipertahankan atau disimpan di dalam ginjal, kristal dapat tumbuh membentuk agregat, yang menghalangi aliran urin yang menyebabkan peningkatan tekanan di dalam ginjal. Hal ini menyebabkan rasa sakit dan ketidaknyamanan (Ankur dkk., 2010).

Penyakit batu ginjal merupakan penyakit yang disebabkan oleh adanyasedimen urin dalam ginjal dan saluran kemih. Batu tersebut akan lebih cepat terbentuk apabila urin sangat pekat dan tidak minum cukup banyak air. Keadaan ini akan sangat mendukung kemungkinan terjadinya pengendapan dari sedimen-sedimen yang terdapat dalam urin sehingga lamakelamaan akan terbentuk suatu massa padat dan keras menyerupai batu (Pramono, 1988). Batu ginjal sedimen terbentuk karena beberapa faktor antara lain minum air putih terlalu sedikit, kurang olah raga, keturunan, makan makanan dengan kandungan asam urat tinggi, mengkonsumsi vitamin yang berlebihan, dan infeksi (Mursito, 2003). Sedimen yang ada di dalam ginjal terbentuk dari bahan-bahan kimia yang umumnya terdapat di dalam air seni seperti kalsium, asam urat, fosfat, dan bahan kimia lain (Hardi, 2005). Kira-kira $80 \%$ batu ginjal tersusun atas kalsium oksalat dan kalsium fosfat, $10 \%$ struvit (magnesium ammonium fosfat), $9 \%$ asam urat dan $1 \%$ sisanya tersusun atas sistin atau ammonium asam urat (Coe dkk., 2005).

Batu ginjal dibagi menjadi beberapa antara lain batu ginjal kalsium, batu asam urat, batu cystin, batu struvit, dan batu kalium fosfat. Sekitar $80 \%$ penderita merupakan penderita batu ginjal kalsium (Soenanto \& Kuncoro, 2005). Batu ginjal mempunyai komponen dasar kalsium $70-80 \%$ baik berupa kalsium oksalat, kalsium fosfat maupun campuran oksalat dan fosfat (Purnomo, 2009). Ginjal merupakan organ penting pada manusia. Ginjal memiliki banyak fungsi seperti pengatur keseimbangan air, konsentrasi garam dalam darah, keseimbangan asam basa darah, ekskresi bahan buangan dan kelebihan garam (Pearce, 2002).

Kalsium yang terdapat dalam batu ginjal dapat dilarutkan dengan kalium (Hutapea, 1994). Kalium akan berkompetisi dan memisahkan ikatan kalsium dengan fosfat/ oksalat sehingga kalsium batu ginjal menjadi terlarut (Suharjo \& Cahyono, 2009). Kandungan kalium dari seledri yang membuat batu ginjal berupa kalsium oksalat terurai, karena kalium akan menyingkirkan kalsium dan bergabung dengan senyawa kalsium oksalat, atau urat yang merupakan pembentuk batu ginjal dengan membentuk senyawa garam yang mudah larut dalam air, sehingga batu ginjal itu akan terlarut secara perlahan-lahan dan ikut keluar bersama urine. Daya melarutkan kalium terhadap endapan kalsium oksalat disebabkan oleh letak kalium di dalam deret volta sebelum letak kalsium, sehingga kalium akan menyingkirkan kalsium untuk bergabung dengan senyawa karbonat, oksalat, atau urat dan senyawa kalsium menjadi larut (Maharani dkk., 2012). Kalium juga membantu mengaktivasi reaksi enzim, seperti piruvat kinase yang dapat menghasilkan asam piruvat dalam proses metabolisme karbohidrat (Winarno, 1992). Tulisan ini bertujuan untuk menentukan efek ekstrak seledri dalam melarutkan kalsium dari batu ginjal dan untuk mengetahui hubungan antara konsentrasi ekstrak seledri dengan daya larut kalsium dalam batu ginjal.

\section{METODE \\ Alat dan Bahan}

Bahan dan alat yang digunakan dalam penelitian ini adalah seledri (Apium graveolens L.) yang berasal dari perkebunan Jono'oge, kecamatan Biromaru, kabupaten Sigi. Bahan kegiatan penelitian dan penyiapan contoh meliputi Batu ginjal yang di peroleh dari 
seorang pasien di RS Undata Palu, Kalsium Fosfat $\left(\mathrm{Ca}_{3}\left(\mathrm{PO}_{4}\right)_{2}\right.$ (Merck), Aluminium foil, Kalsium (Ca) 1000 ppm (Ajax), Aquadest, Flame Fotometer BWB XP, Ayakan No.53 mesh, Neraca analitik, Magnetik Stirer, Penangas.

\section{Cara Kerja \\ Pembuatan ekstrak seledri}

Sejumlah herba seledri dicuci hingga bersih, dipotong-potong, dikeringkan dan di tumbuk sampai halus. Kemudian menimbang sebanyak 300 gram dan dimasukkan ke dalam gelas kimia. Lalu menambahkan aquadest sampai $1000 \mathrm{~mL}$, kemudian direbus hingga ekstrak menjadi $300 \mathrm{~mL}$ dan mendinginkannya. Setelah dingin, ekstrak disaring kedalam wadah yang lain dan diperoleh berupa ekstrak pekat. Setelah itu ektrak pekat tersebut divariasikan menjadi ekstrak $(1 \%, 5 \%, 10 \%, 15 \%$, dan 20\%) (Pelani, 2008).

\section{Penyiapan Batu Ginjal}

Batu ginjal kalsium oksalat-fosfat sebagai sampel digerus hingga menjadi butiran-butiran dalam bentuk serbuk lolos ayakan no. 53 mesh sehingga diperoleh serbuk yang homogen.I

\section{Identifikasi Batu Ginjal}

Untuk identifikasi kalsium batu ginjal dapat dilakukan analisis berupa bentuk dan warna kalsium batu ginjal. Identifikasi yang dilakukan secara makroskopik dari kalsium batu ginjal, meliputi warna, bentuk dan permukaan. Hal ini dilakukan untuk memastikan bahwa batu ginjal kasium yang digunakan adalah batu ginjal dari jenis kalsium dengan spesifikasi yang sudah di ketahui. Hasil pengamatan yang diperoleh batu ginjal yang digunakan pada penelitian ini adalah jenis batu ginjal kalsium oksalat-fosfat dengan permukaannya kasar dan memiliki warna coklat muda.

\section{Pembuatan Kurva Kalibrasi}

Dari larutan standar Kalsium 1000 ppm dibuat deret standar sebagai berikut: $0 \mathrm{ppm}$, 20 ppm, 40 ppm, 60 ppm, 80 ppm, dan 100 ppm dengan melakukan pengenceran larutan tersebut. Kemudian labu takar masing-masing diisi dengan larutan standar kalsium sebanyak 0 $\mathrm{mL}, 10 \mathrm{~mL}, 20 \mathrm{~mL}, 30 \mathrm{~mL}, 40 \mathrm{~mL}$, dan $50 \mathrm{~mL}$, lalu ditambahkan dengan air hingga volumenya tepat sampai tanda batas $50 \mathrm{~mL}$, kecuali untuk larutan standar kalsium $50 \mathrm{~mL}$ tidak perlu ditambahkan dengan air karena volumenya sudah tepat $50 \mathrm{~mL}$. Setelah itu, serapannya diukur dengan menggunakan Flame fotometer. Kemudian membuat kurva kalibrasi dengan menggunakan Microsoft Excel.

\section{Uji Daya Larut}

Ekstrak seledri dibuat dengan variasi $1 \%$, $5 \%, 10 \%, 15 \%$, dan 20\%, masing-masing dibuat sebanyak $100 \mathrm{~mL}$. Kemudian ekstrak seledri pada konsentrasi 1\%, 5\%, 10\%, 15\%, dan $20 \%$ diambil masing-masing sebanyak $25 \mathrm{~mL}$ pada setiap konsentrasi. Lalu serapan kalsium diukur dengan menggunakan Flame fotometer sebagai data sebelum penambahan kalsium fosfat. Setelah itu, kalsium fosfat 0,1 gram ditambahkan ke dalam masing-masing Erlenmeyer yang berisi $25 \mathrm{~mL}$ ekstrak seledri, lalu menutupnya dengan menggunakan aluminium foil. Kemudian campuran tersebut dikocok selama 24 jam dengan menggunakan alat pengocok (magnetik stirer). Larutan hasil pengocokan kemudian didiamkan dan disaring dengan menggunakan kertas saring. Setelah itu, filtratnya ditampung untuk penentuan kadar kalsium dengan menggunakan Flame fotometer sebagai data setelah penambahan kalsium fosfat (Pelani, 2008).

\section{Hasil dan Pembahasan}

Pada penelitian ini seledri (apium graveolens L.) diperoleh dari perkebunan Jono'oge, Kecamatan Biromaru, Kabupaten Sigi.

\section{Penentuan Kurva Kalibrasi Standar Ca}

Dari hasil pengukuran serapan larutan standar Ca dengan Flame fotometer diperoleh data sebagai berikut :

Tabel 1. Data Serapan Larutan Standar Ca

\begin{tabular}{cc}
\hline Standar Ca $(\mathrm{ppm})$ & Absorban \\
\hline 0 & 11,10 \\
20 & 32,30 \\
40 & 55,30 \\
60 & 81,60 \\
80 & 105,10 \\
100 & 131,50 \\
\hline
\end{tabular}

Dengan menggunakan persamaan regresi linier hubungan antara konsentrasi $\mathrm{Ca}$ dengan serapan diperoleh persamaan $\mathrm{y}=(1,235) \mathrm{x}+$ 8,319 dan nilai $r=0,997$

\section{Uji belarutan Batu Ginjal}

Penentuan Kadar Ca Dalam Ekstrak Seledril

Pada pengukuran serapan Ca dalam ekstrak seledri diperoleh data serapan dan konsentrasi 
sebagai berikut :

Tabel 2. Data Serapan Variasi Ekstrak Seledri Terhadap Konsentrasi Kalsium

\begin{tabular}{cccccc}
\hline $\begin{array}{c}\text { Konsentrasi } \\
\begin{array}{c}\text { Seledri } \\
(\% v / v)\end{array}\end{array}$ & $\begin{array}{c}\text { Absorban } \\
\text { Sebelum } \\
\text { Pengocokan }\end{array}$ & $\begin{array}{c}\text { Absorban } \\
\text { Setelah } \\
\text { Pengocokan }\end{array}$ & $\begin{array}{c}\text { Faktor } \\
\text { Pengenceran } \\
\text { (Kali) }\end{array}$ & $\begin{array}{c}\text { Konsentrasi } \\
\text { Ca Sebelum } \\
\text { Pengocokan } \\
\text { (pom) }\end{array}$ & $\begin{array}{c}\text { Konsentrasi } \\
\text { Ca Setelah }\end{array}$ \\
$\begin{array}{ccccc}\text { Pengocokan } \\
\text { (ppm) }\end{array}$ \\
\hline 1 & 11,10 & 11,52 & - & 2,251 & 2,591 \\
5 & 45,20 & 52,10 & - & 29,863 & 35,450 \\
10 & 76,38 & 92,50 & - & 55,110 & 68,162 \\
15 & 22,21 & 26,22 & 5 & 56,235 & 72,470 \\
20 & 23,87 & 29,32 & 5 & 62,955 & 85,020 \\
\hline
\end{tabular}

Tabel 3.Data Peningkatan Ca Pada Ekstrak Seledri Setelah Pengocokan dengan

PenambahkanKalsium Fosfat

\begin{tabular}{ccccc}
\hline \multirow{2}{*}{$\begin{array}{c}\text { Konsentrasi } \\
\text { Seledri } \\
(\% \text { Kv v })\end{array}$} & $\begin{array}{c}\text { Sebelum } \\
\text { ditambahkan } \\
\text { dengan kalsium } \\
\text { fosfat }\end{array}$ & $\begin{array}{c}\text { Sesudah } \\
\text { ditambahkan } \\
\text { dengan } \\
\text { kalsium fosfat }\end{array}$ & $\begin{array}{c}\text { Selisih } \\
\text { Konsentrasi } \\
(\mathrm{ppm})\end{array}$ & $\begin{array}{c}\text { Peningkatan } \\
\text { Kadar Ca }(\%)\end{array}$ \\
\hline 1 & 2,251 & 2,591 & 0,340 & 15,104 \\
5 & 29,863 & 35,450 & 5,587 & 18,708 \\
10 & 55,110 & 68,162 & 13,052 & 23,683 \\
15 & 56,235 & 72,470 & 16,235 & 28,869 \\
20 & 62,955 & 85,020 & 22,065 & 35,048 \\
\hline
\end{tabular}

Berdasarkan Tabel 3. dapat dibuat kurva hubungan antara konsentrasi seledri terhadap peningkatan kadar $\mathrm{Ca}(\%)$ sebagai berikut

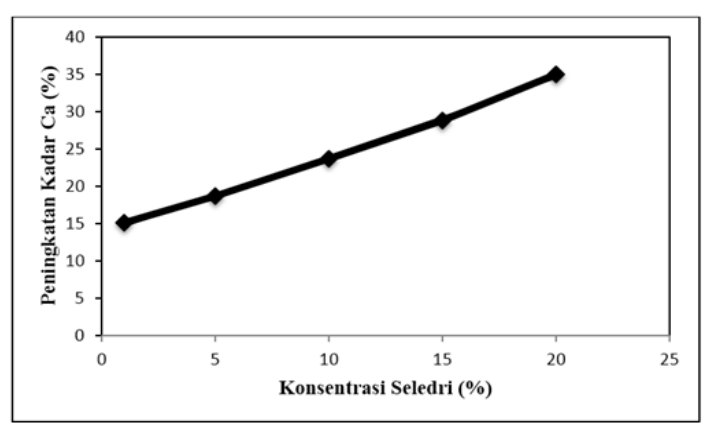

Gambar 1. Kurva Hubungan Antara

Konsentrasi Seledri (\%) Terhadap Peningkatan Kadar Ca (\%).

Larutan standar yang digunakan yaitu larutan kalsium standar $1000 \mathrm{ppm}$, dibuat deret baku dengan konsentrasi 0 ppm, 20 ppm, $40 \mathrm{ppm}, 60 \mathrm{ppm}, 80 \mathrm{ppm}$, dan $100 \mathrm{ppm}$. Konsentrasi larutan standar yang bervariasi ini dilakukan agar nantinya diperoleh suatu grafik yang memiliki garis linear yang mengikuti hukum Lambert-Beer yaitu absorbansi berbanding lurus dengan konsentrasi uap atom dalam nyala. Absorbansi yang diperoleh dari kalsium standar secara berturut-turut yaitu 11,$10 ; 32,30 ; 55,30 ; 81,60 ; 105,10$; dan 131,50 .

Selanjutnya melakukan uji kelarutan batu ginjal, dimana sebelum diujikan dengan batu ginjal, terlebih dahulu diujikan dengan kalsium fosfat karena kalsium fosfat salah satu komposisi batu ginjal. Selain itu juga agar batu ginjal yang dibutuhkan tidak terlalu banyak, mengingat karena batu ginjal sulit diperoleh. Dalam uji kelarutan batu ginjal ini sampel dibuat menjadi beberapa variasi konsentrasi yaitu konsentrasi $1 \%, 5 \%, 10 \%, 15 \%$, dan $20 \%$. Hal ini dilakukan untuk mengetahui tingkat kelarutan kalsium dalam batu ginjal, maka perlakuannya dibuat sama pada setiap sampel hanya saja konsentrasinya dibedakan. Setelah membuat konsentrasi ekstrak seledri, selanjutnya dilakukan dua kali perlakuan dimana perlakuan pertama sampel belum ditambahkan kalsium fosfat, sedangkan perlakuan kedua sampel telah ditambahkan 0,1 gram kalsium fosfat kemudian dikocok selama 24 jam menggunakan magnetik stirer. Tujuannya adalah untuk mendapatkan kondisi seperti yang terjadi dalam tubuh, khususnya dalam organ ginjal yang kemudian bergerak kesaluran kemih sebagai tempat biasa ditemukannya batu ginjal itu sendiri (Lusiyanah, 2011). Setelah itu larutan didiamkan, selanjutnya disaring sehingga diperoleh filtratnya kemudian diukur absorbansinya dengan menggunakan flame fotometer.

Berdasarkan Tabel 3 dan kurva pada Gambar 1 diperoleh informasi bahwa dengan meningkatnya konsentrasi ekstrak seledri maka semakin banyak kalsium dari batu ginjal yang terlarut dinyatakan dalam peningkatan kadar Ca (\%), maka dari data pada Tabel 3 ini dapat dilihat bahwa pada konsentrasi $1 \%$ hingga 20\% peningkatan kadar Ca bertambah. Meningkatnya konsentrasi ekstrak seledri tersebut juga meningkatkan absorbansinya, dimana kadar kalsium yang terlarut dalam ekstrak seledri dapat dilihat dari selisih antara konsentrasi kalsium sebelum dan sesudah penambahan batu ginjal (Lusiyanah, 2011). Nilai selisih konsentrasi yang diperoleh pada masing-masing konsentrasi dapat dilihat pada Tabel 3, dimana dari Tabel 3 dapat dibuat kurva perbandingan antara konsentrasi seledri (\%) terhadap peningkatan kadar Ca (\%).

Setiap konsentrasi ekstrak seledri yang belum ditambah kalsium posfat dan yang telah ditambah kalsium fosfat dianalisis kalsiumnya 
dengan mengunakan flame fotometer, dari hasil absorbansi yang diperoleh dapat menentukan konsentrasi kalsium pada masingmasing konsentrasi sampel baik yang sebelum ditambah kalsium posfat dan yang telah ditambah kalsium posfat seperti tertera pada Tabel 3.

Kurva pada Gambar 1 menunjukan bahwa ektrak seledri dapat melarutkan kalsium dalam kalsium posfat, dimana semakin besar konsentrasi ekstrak seledri maka semakin banyak kalsium yang terlarut, ini dapat dilihat dari nilai selisih konsentrasinya. Ini disebabkan karena adanya efek dari ion sekutu dan ion asing. Ion sekutu adalah suatu ion yang juga merupakan salah satu bahan endapan. Umumnya dapat dikatakan bahwa kelarutan suatu endapan dapat berkurang jika salah satu ion sekutu terdapat dalam sampel. Dalam hal ini kalsium merupakan ion sekutunya karena terdapat pada ekstrak seledri sebelum maupun sesudah penambahan kalsium posfat, namun karena adanya ion asing pada ekstrak seledri tersebut, sehingga dapat meningkatkan kelarutan kalsium pada kalsium posfat (Lusiyanah, 2011).

Salah satu faktor yang mempengaruhi kelarutan kalsium yaitu adanya kalium yang terkandung dalam ekstrak seledri. Ion-ion kalium yang cukup tinggi, dapat menjaga keseimbangan elektrolit pada ginjal. Kalium inilah yang membuat batu ginjal terurai, karena kalium akan menyingkirkan kalsium dan bergabung dengan senyawa kalsium fosfat yang merupakan pembentuk batu ginjal dengan membentuk senyawa garam yang mudah larut dalam air, sehingga batu ginjal itu akan terlarut secara perlahan-lahan dan ikut keluar bersama urine dengan reaksi kimia sebagai berikut (Hidayati dkk., 2009).

$$
6 \mathrm{~K}^{+}+\mathrm{Ca}_{3}\left(\mathrm{PO}_{4}\right)_{2} \longrightarrow 2 \mathrm{~K}_{3} \mathrm{PO}_{4}+3 \mathrm{Ca}^{2+}
$$

\section{Kesimpulan}

Ekstrak seledri memiliki efek melarutkan kalsium dalam batu ginjal jenis kalsium oksalatfosfat. Kelarutan kalsium dalam batu ginjal berbanding lurus dengan konsentrasi ekstrak seledri. Sehingga semakin tinggi konsentrasi ekstrak seledri maka kelarutan kalsium semakin besar.

\section{Ucapan Terima Kasih}

Penulis mengucapkan terimakasih sebesarbesarnya kepada kepala laboran laboratorium Agroteknologi Fakultas Pertanian dan semua pihak yang telah membantu dalam pelaksanaan penelitian.

\section{Referensi}

Ankur, C., Amarchand, P., Aadarsh, C., \& Deepa, I. (2010). Potential of medicinal plants in kidney, gall and urinary stones. International Journal of Drug Development and Research, 2(2), 431-447.

Coe, F. L., Evan, A., \& Worcester, E. (2005). Kidney stone disease. Journal Clin Inverst, 115, 2598-2608.

Dalimartha, S. (2000). Atlas tumbuhan obat indonesia jilid II. Jakarta: PT. Trubus Agriwidya.

Dalimartha, S. (2002). Resep tumbuhan obat untuk penderita osteoporosis. Jakarta: Penebar Swadaya.

Hardi, S. (2005). Hancurkan batu ginjal dengan ramuan herbal. Jakarta: Puspa Swara.

Hidayati, A., Yusrin, \& Anggraini, H. (2009). Pengaruh frekuensi penggunaan teh daun tempuyung kering (sonchus arvensis) terhadap daya larut kalisum oksalat (CaC2O4). Jurnal Kesehatan, 2(2), 30-37.

Hutapea, J. R. (1994). Inventaris tanaman obat indonesia edisi III. Jakarta: Departemen Kesehatan Republik Indonesia Badan Penelitian dan Pengembangan Kesehatan.

Ismadi. (1978). Kuliah penyegaran nefrologi. Yogyakarta: Fakultas Kedokteran Universitas Gadjah Mada.

Lusiyanah. (2011). Pengaruh konsentrasi ekstrak akar dari akar kucing (acalypha indica) terhadap kelarutan kalsium pada batu ginjal. Palu: Universitas Tadulako.

Maharani, E. T., Mukamorah, A. H., \& Susilo, J. (2012). Analisis kalium dan prosentase daya larut kalsium oksalat oleh kalium dalam air teh daun sukun (artocarpus altilis). Semarang: Fakutas Farmasi Universitas Muhammadiyah Semarang.

Mursito, B. (2003). Ramuan tradisional untuk gangguan ginjal. Jakarta: Penebar Swadaya. 
Pearce, E. C. (2002). Anatomi dan fisiologi untuk paramedis. Jakarta: PT. Gramedia Pustaka.

Pelani. (2008). Pengaruh ekstrak daun alpukat (persea americana mill) terhadap kelarutan dari kalsium batu ginjal. Skripsi Palu: Universitas Tadulako.

Pramono, S. (1988). Buku temu risalah temu ilmiah 1987 fakultas farmasi UGM. Yogyakarta: Fakultas Farmasi UGM.

Purnomo, B. B. (2009). Dasar-dasar urologi. Jakarta: CV. Sagung Seto.

Rajat, M., Anu, W., \& Sumeet, G. (2011). New frontiers on nephrolithiasis: phatophysiologi and management of kidney stones. International Journal of Research in Ayurveda \& Pharmacy, 2(3), 775-785.

Rukmana, R. (1995). Bertanam seledri. Yogyakarta: Kanisius.

Soenanto, S., \& Kuncoro, S. (2005). Hancurkan batu ginjal dengan ramuan herbal. Jakarta: Puspa Swara.

Suharjo, S. B., \& Cahyono, B. (2009). Batu ginjal. Yogyakarta: Kanisius.

Wientarsih, I. (2008). Daun alpukat mampu obati batu ginjal. Bogor: Institut Pertanian Bogor.

Winarno, F. G. (1992). Kimia pangan dan gizi. Jakarta: PT. Gramedia Pustaka Utama. 